\title{
FILOSOFIAS EM DIÁSPORA: EPISTEMOLOGIAS DE TERREIRO E TRANSFORMAÇÓES DO EU
}

\author{
Luis Thiago Freire Dantas ${ }^{1}$
}

\begin{abstract}
Resumo: Este artigo trata da diáspora africana como fonte epistemológica e, principalmente, de pensar suas implicaçóes para a produção de filosofia africana, no Brasil. Para isso, o corpo será enfatizado como meio de comunicação com o mundo visível ou invisível, através do terreiro, estabelecendo uma relação entre a vivência e o pensamento filosófico. Em seguida, para fundamentar a diáspora, será interpretada a narrativa da orixá Oyá/Iansấ, tendo como eixo o "corpo sem fronteiras" que medeia natureza e cultura. Por fim, propóe-se uma filosofia que articule o encontro entre o terreno e o espiritual, a tradiçăo e o moderno, baseando-se em uma conexão conceitual entre África e Brasil.
\end{abstract}

Palavras-chave: Filosofia Africana. Diáspora. Terreiro. Corpo.

\section{INTRODUÇÁO}

A proposta de articular uma filosofia a partir do horizonte do "Sul global” demanda uma percepção acerca da condição de "[...] possibilidade de uma reforma cultural profunda em nossa sociedade, depende da descolonização dos nossos gestos, de nossos atos, e da língua com que nomeamos o mundo.” (CUSICANQUI, 2010, p. 71). Isso se alarga, quando observamos as ciências humanas que, no seu surgimento, pretendiam julgar o ser humano, tentando

${ }_{1}^{1}$ Professor Adjunto de Filosofia da Educação pela Universidade do Estado do Rio de Janeiro (UERJ), Rio de Janeiro, RJ - Brasil. (D) https://orcid.org/0000-0001-8524-8213. E-mail: luis.dantas@uerj.br.

$2 \mathrm{O}$ termo "Sul global" torna-se um uso recorrente no fim da Guerra Fria e com a propagação da noção de Globalização, como um discurso e dinâmica de alargamento, perante os países pobres e em desenvolvimento. Também o termo "Sul global" desatualiza o termo "Terceiro Mundo", que considerava o estágio de economia dos países em busca do parâmetro de modernidade. Para saber mais sobre o projeto político de "Sul global", ver BALLESTRIN, 2020.

https://doi.org/10.1590/0101-3173.2022.v45esp.10.p169

\section{(i)}


produzir um conhecimento distanciado do mundo, ou seja, uma separação entre o sujeito da pesquisa e o objeto pesquisado, fato propiciado por uma ideia regulativa de ser humano que posiciona as culturas dos "outros" como subalternas. No entanto, desde a metade do século XX, o surgimento de alternativas epistemológicas problematizou as ciências humanas na construção de epistemes, enfatizando as variedades culturais e os entendimentos acerca da natureza. Nesse caminho, a filosofia também foi deslocada de uma posição centrada no Norte global, orientando os princípios daquilo definido como ser humano, para movimentar-se em uma série de diálogos com os diferentes territórios. Tal posição requereu outras nomeações sobre a filosofia, pois “[...] o fato de que a 'filosofia' se tornou global não significa que também é 'universal'." (MIGNOLO, 2008, p. 298).

Para ilustrar essa situação além do "uni-versal", fazemos uso de um trecho da carta de Grada Kilomba (2017) à edição brasileira de Memórias da Plantação, a fim de destacar a busca por outras linguagens epistêmicas. A autora comenta como a mudança de Lisboa para Berlim a fez sair de um local de negação e glorificação para um de culpa e vergonha sobre a própria história. Essa característica de Berlim, conforme percepção de Kilomba, perpassou diversas etapas, como negação, culpa, vergonha, reconhecimento e reparação que, ao fim, invocaram uma noção coletiva em "[...] criar novas configuraçóes de poder e de conhecimento.” (KILOMBA, 2017, p. 11).

Partindo desse horizonte coletivo de criação, o presente artigo tratará do diálogo entre as epistemologias africanas e afro-brasileiras, para, a partir daí, anunciar uma filosofia em diáspora, ou seja, uma filosofia em contínua dispersão e firmamento de um "eu". Um "eu" reproduzido tal como na urgência de Kilomba (2017, p. 11) em sair de Lisboa e aprender um "[...] novo vocabulário, no qual eu pudesse finalmente encontrar-me. No qual eu pudesse ser $e$ u." Tal encontro é marcado tanto pela ausência de espaço quanto pela sensação permanente de estar "fora de casa”, pois, na maioria das vezes, necessita de um confronto com as estruturas-padrão de poder: "Só quando se reconfiguram as estruturas de poder é que as muitas identidades marginalizadas podem também, finalmente, reconfigurar a noção de conhecimento: Quem sabe? Quem pode saber? Saber o quê? E o saber de quem?” (KILOMBA, 2017, p. 13, grifo da autora). São perguntas emanadas como questionamento à conjuntura marginal de identidades e à obstrução de escutar certas vozes.

A compreensão dessa marginalização e obstrução aponta para a posição ocidental em discursar sobre os "outros", a partir de uma "cosmovisão" 
que privilegia a organização dos povos não ocidentais conforme categorias hierarquizantes de humanidade. Uma hierarquia proporcionada justamente, segundo Oyèrónkẹ́ Oyěwùmí (2020), pela restrição ao campo visual: "A diferenciação dos corpos humanos em termos de sexo, cor da pele e tamanho do crânio é um testemunho dos poderes atribuídos ao 'ver'. O olhar é um convite para diferenciar." (OYĚWÙMÍ, 2021, p. 29). Por isso, a "cosmopercepção" (worldsense), para a autora, adequa-se aos povos que não se restringem à visão e sim compreendem uma conexão sensorial para perceber o mundo e organizálo. Então, o ato de criar uma linguagem para afirmar um "eu" (KILOMBA, 2017) e de organizar o mundo na combinação dos sentidos (OYĚWÜMÍ, 2021) será nosso guia para construir um diálogo filosófico entre África e Brasil.

Tal diálogo necessita de um duplo aprofundamento: o conceito de diáspora como elemento espaço-temporal e das consequências para o pensamento filosófico africano, no afro-brasileiro. Para isso, o corpo será enfatizado como eixo principal para o debate, em sua comunicação com o mundo visível e invisível. Primeiro, o intuito é analisar como o corpo aparece na "reterritorializaçâo" (SODRÉ, 2019) de África, no território brasileiro, através do terreiro e, por conseguinte, como estabelecer, a partir do corpo, uma relação entre a vivência e o pensamento filosófico. Construindo essa relação, a diáspora constitui fonte epistemológica para uma articulação filosófica, com base no princípio da transformação de Oyá/Iansãa , que molda o "corpo sem fronteiras" entre natureza e cultura. Com tais consideraçóes, neste artigo, almeja-se o encontro, a comunicação entre o terreno e o espiritual, a tradição e o moderno como cruzamentos conceituais entre África e Brasil.

\section{UM CORPO NO MUNDO}

A expropriação material causada nos africanos pelo tráfico transatlântico teve como uma das consequências a deslegitimação da memória, ou melhor, o não reconhecimento do próprio passado. Em decorrência, o argumento colonial alterou o significado de retorno ancestral para um retorno mítico que provoca a sensação de um exílio permanente. Outro efeito da expropriação da memória trata-se da junção entre colonialismo, escravidão e apartheid, a qual condicionou a naturalização de tragédia para os africanos. Achille Mbembe (2001) entende que essa naturalização para o Ocidente funciona como a

3 Divindade do panteâo iorubano, uma Orixá que se manifesta, especialmente, por meio dos ventos e dos raios. 
impossibilidade de um mundo sem outros e também atribui "[...] o peso da responsabilidade específica que abate sobre os próprios africanos, face à tragédia em sua história." (MBEMBE, 2001, p. 188).

Com esse horizonte, a escravização negra nas Américas passa a simbolizar a fragmentação da memória e a permanência de uma ferida atuante no "domínio psíquico" de africanos em diáspora. Esse "domínio psíquico", sintetizado pela máscara colonial, conforme análise de Kilomba, impóe o silêncio aos negros colonizados, transformando a ferida (the wound) em um sintoma relacional entre a população negra e a branca. Essa relação acontece pela construção identitária do "mundo branco" a partir do ato de inferiorizar o "mundo negro". Entre esses e outros motivos, o trauma negro não se forma estritamente no bojo familiar, mas, primordialmente, no contato com o exterior:

Parece, portanto, que o trauma de pessoas negras provém não apenas de eventos de base familiar, como a psicanálise argumenta, mas sim do traumatizante contato com a violenta barbaridade do mundo branco, que é a irracionalidade do racismo que nos coloca sempre como a/o "Outra/o", como diferente, como incompatível, como conflitante, como estranha/o e incomum. (KILOMBA, 2017, p. 40).

Com a violência proveniente do mundo "branco", um tipo de "esquecimento" distante do significado comum foi produzido como drama familiar e incrustado na própria existência. A saída foi ocultar a própria ancestralidade. Por isso, a narrativa escravocrata de povos africanos nas plantations das Américas compara-se à presença de um fantasma no corpo que, para "ter" uma existência atual, é "[...] necessário esquecer o nome do pai no próprio instante no qual se afirma levantar a questão da origem e da filiação." (MBEMBE, 2001, p. 189). Porém, o mesmo corpo expropriado possibilita uma potência epistemológica, pois a pessoa negra tem no corpo o meio de expressão de sua identidade e da criação de história.

Com o intuito de criar histórias, a dinâmica do corpo negro nas Américas e, principalmente, no Brasil, acontece em territórios que tendem a resgatar a ancestralidade africana em novas terras. Entre tais territórios, destaca-se o terreiro, pois nele circula a experiência daqueles que ali habitam, seja no campo visível, seja no invisível. Aliás, para Muniz Sodré (2019, p. 54) o terreiro "[...] é uma África 'qualitativa' que se faz presente, condensada, reterritorializada." Tal África "qualitativa”, no contexto brasileiro, compóe um 
lugar de resistência e de humanidade, o qual reserva o significado de memória coletiva da cultura africana: "[...] um patrimônio simbólico consubstanciado no saber vinculado ao culto aos muitos deuses, à institucionalização das festas, das dramatizações dançadas e das formas musicais." (SODRÉ, 2019, p. 53).

Esse conjunto acontece através de uma comunidade litúrgica, o Egbé, com a estratégia de unificar grupos populacionais distintos, pois, se, no continente africano, cada sociedade tinha uma ligação específica a um determinado orixá, no Brasil, os vários cultos se aglutinam em um espaço que funciona como autofundação de grupos em diáspora. Por isso, o terreiro converge em uma importância singular, já que demarca o território, a linhagem ou, ainda, "[...] o conjunto das relaçôes de ascendência e descendência regidas por uma ancestralidade que não se define apenas biologicamente, mas também política, mítica e ideologicamente.” (SODRÉ, 2019, p. 71).

Tais especificidades são repletas de uma complexidade de relações, sintetizadas no axé, na força vital, que, como afirma Sodré (2019, p. 98), “[...] é capaz de gerar espaço." Um espaço que permite visualizar o terreiro como um território filosófico. Partir dessa afirmaçãa é precisamente compreender o terreiro na posição de comunidade litúrgica, significando "obra de povo", que não se aproxima de demos, mas de Laós - uma força do consenso - por atribuir “[...] ação comunitária regida pelo sagrado.” (SODRÉ, 2019, p. 90). O sagrado, nesse sentido, constitui uma mediação entre humanos e divindades, por meio do corpo que se expande politicamente e recria histórias:

A comunidade-terreiro é, assim, repertório e núcleo reinterpretativo de um patrimônio simbólico explicitado em mitos, ritos, valores, crenças, formas de poder, culinária, técnicas corporais, saberes, cânticos, ludismos, língua litúrgica (o ioruba) e outras práticas sempre suscetíveis de recriação histórica, capazes de implementar um laço atrativo de natureza intercultural (negros e negros) e transcultural (negros e brancos). (SODRÉ, 2015, p. 195-196).

Nesse entrelaçamento, manifesta-se a herança cultural que, para Vanda Machado (2013), expóe o conjunto de saberes: o mito, o canto, a dança, os provérbios, as diversas narrativas vivenciadas. Um conjunto composto pelos acontecimentos do mundo e expressado pelo ato de educar " [...] em-sinando na extraordinariedade do cotidiano.” (MACHADO, 2013, p. 41). Ênfase no cotidiano, pois, divergindo do monoteísmo ocidental, no qual o profano 
marca as vivências plurais mundanas, no pluriteísmo ${ }^{4}$ africano, o cotidiano adquire importância pela feitura, um elo importante de autoconhecimento: "Nas comunidades de terreiro, o mundo é singular e plural pelas vivências mitológicas. Cada um vive um cotidiano só compreensível por aqueles que passaram pela experiência da feitura." (MACHADO, 2013, p. 43). Dessa maneira, podemos afirmar que o "conhece-te a ti mesmo" aqui é expresso por uma vivência regulada não apenas pela continuidade e expansão coletiva do grupo, como também pelo acolhimento aos outros.

Com essas características, o espaço do terreiro como aquele em que circula o axé se se constitui em um lugar atemporal, caracterizado por métodos próprios de aprender e de ensinar: "Os nossos mais velhos aprenderam a fazer observando, imitando e admirando os seus mais velhos nos seus saberes e fazeres." (MACHADO, 2013, p. 41). Acompanhando Machado, o ato de ensinar no terreiro tem como horizonte "[...] colocar o outro dentro do seu $o d u$, dentro da sua própria sina, do seu caminho, do seu jeito de ser no mundo do jeito como ele é." (MACHADO, 2013, p. 41). Por isso, para a autora, o ensino passa a ser em-sino, ou seja, conduzir a pessoa para o próprio destino.

Certos elementos, como sonhos, desejos e utopias, são considerados como necessários para a formação da pessoa, a qual, em decorrência, junta o ato de filosofar às vivências cotidianas. Uma junção que resulta na percepção dos acontecimentos triviais como extraordinários, já que aquilo que nos afeta pode contribuir para a construção de nosso modo de ser. Acrescente-se que esse modo não acontece por si somente, porém, na comunicação que envolve a tríade do ser, do fazer e do participar:

No terreiro, pelas vivências, aprende-se a ser-sendo participando dos fazeres comunitários. Busca-se, então, compreender mais profundamente o ser. Esta é a condição para complementaridade entre os acontecimentos e a qualidade do que se é essencialmente. No terreiro, aprende-se pela rememoração vivenciada seguindo múltiplos códigos de comportamentos específicos para a vida comunitária comprometida, inclusiva e solidária. (MACHADO, 2013, p. 42).

Tais comportamentos se fundamentam na conexão com os ancestrais que não estão situados em um passado, mas interagem no presente, mediados

${ }^{4}$ Utilizamos o termo pluriteísmo, ao invés de politeísmo, para marcar as interpretaçóes plurais de divindades possíveis no nosso corpo mediúnico: orixás, voduns, inquices, erês, espíritos, caboclos/ as, boiadeiros/as, marujos/as, exus, pomba-giras, entre tantos/as outros/as; caso contrário, permaneceríamos com uma interpretação indiferente às múltiplas manifestações. 
pelo corpo. Com isso, a memória é uma atualização do presente, e não um elemento fixado pelo que passou, principalmente pelos valores conectados ao coletivo que "[...] persistem na família, na vizinhança, apoiando a memória e a cultura do lugar." (MACHADO, 2013, p. 50). Por consequência, a história torna-se uma construção de acontecimentos afirmados pelo presente e resgatados pelas memórias do povo. Por fim, a memória torna-se assim um elemento de potencialização da identidade coletiva e reorganiza a mente ancestral para uma África múltipla e atual:

Essa é a ideia que nos remete a valores que estáo na raiz, no sentimento e no pensamento africano. Pensamento que não atende à disciplinaridade nem a fragmentação que mutila a educação. Atende, sim, aos princípios da tradição em suas peculiaridades tendo como fundamento uma cosmovisão no presente e que se alarga plural. (MACHADO, 2013, p. 52).

Trata-se de um alargamento que aciona uma compreensão acerca da vida e seus fenômenos como complemento a todos habitantes do mundo. Essa possibilidade provém da filiação da filosofia africana com eixos como “[c]orpo, mente, memória, tradição, sentidos, imaginário, símbolos, signos, espiritualidade e as vivências cotidianas" (MACHADO, 2013, p. 52) que definem uma reexistência, na diáspora. Tal reexistência, para Machado, se organiza como uma identidade ancestral revelada pela oralidade e por uma epistemologia enraizada no atemporal:

Neste sentido, a matriz cultural africana vivenciada nos terreiros carrega, na sua gênese, um conteúdo nem sempre simbólico, com princípios e valores que vão se reorganizando e nos organizam, dialogando com entidades de todos os tempos para os quais viver é um ato sagrado, e nós recebemos este legado. Aprofundar no mistério, no sagrado, e compreendê-lo é diferente de explicar. (MACHADO, 2013, p. 53).

Nesse caminho, há uma transformação do "Eu" por adquirir diferentes formas em determinados espaços no interior do terreiro, já que a ocupação de funçôes modifica tanto a pessoa quanto a comunidade. Em certo sentido, pela ocupação, constroem-se identidades que estão em referência à demarcação de espaço na diferença com os outros. Uma diferença, para Sodré (2019), que estabelece o território como "[...] o lugar marcado de um jogo, que se entende em sentido amplo como a protoforma de toda e qualquer cultura: sistema de regras de movimentação humana de um grupo, horizonte de relacionamento 
com o real.” (SODRÉ, 2019, p. 25). Desse modo, o corpo negro passa também a ser um território:

Território do corpo, relacionado com o espaço pessoal, como o próprio corpo e o espaço adjacente - esta é uma delimitaçáo invisível do espaço que acompanha o indivíduo, sendo capaz de se expandir ou contrair-se de acordo com a situação e caracterizando-se, portanto, pela flexibilidade. (SODRÉ, 2019, p. 39, grifos do autor).

Com tal flexibilidade, o território do corpo negro produz conhecimento através das expressóes, resistindo à "violência epistêmica", a qual, no caso brasileiro, incide na atribuição de ausência de qualquer refinamento e cortesia em detrimento àquilo que o espaço urbano procurou reproduzir enquanto aparência europeia. Essa associação teve como efeito um processo produtivo imbuído de uma lógica de segregação territorial "[...] na distribuição de terras no interior do território urbano.” (SODRÉ, 2019, p. 42). Por isso, fazendo uso da flexibilidade, o corpo situado no terreiro expressa-se como um entre-lugar que categoriza a invenção, a descoberta e a rememoração como elementos filosóficos. E o território do corpo negro possibilita contextos abertos ao contato e à transformação humana, que, por fim, ressignificam as fronteiras entre natureza e cultura.

\section{CORPo SEM FronteIRAS}

As estratégias coloniais para o apagamento da memória, nos africanos escravizados, encontraram resistência justamente nas expressóes corporais em produçóes territoriais de vivência ancestral. O território, enfatizado neste artigo, tratou do terreiro e, principalmente, dos modos de "em-sino" que marcam a produção de conhecimento através do "eu" transformado coletivamente, "[...] a partir de condiçóes que incluem a ancestralidade, a memória, o corpo, o tempo e o espaço" (MACHADO, 2013, p. 19). Tais elementos compóem uma filosofia fundamentada na diáspora africana.

Para explicar essa fundamentação, associamos à figura do oceano Atlântico um tráfego permeado pela violência e pelo controle de populaçóes. Tal associação reflete acerca do sentido e dos afetos daquelas pessoas que nascem em diáspora, pois a entendemos como produção de corpos deslocados ou, 
ampliando uma expressão de Kilomba5 (2017, p. 62), "corpos fora do lugar”. Tal perspectiva é aqui utilizada com o intuito de opor-se à noção de "entrelugar”, pois, conforme análise de Stuart Hall (2009, p. 109), nessa definição, entende-se a diáspora funcionando como uma "utopia da diferença”, em que o "Outro" seria como "uma posição marcada de forma diferencial dentro da cadeia discursiva" e não sofreria interferências da mobilidade do tempo e do espaço. Já o "fora do lugar" destaca um modo de ser em contínua construção e sem uma determinação local, porque, a cada momento, requer um conflito perante a situação de ser outrem. Essa condição pode ser exemplificada através da resposta da socióloga Avtar Brah (2011), ao questionamento de um estadunidense se o pertencimento geográfico da autora seria Uganda ou Índia:

Em princípio esta pergunta me parecia absurda. Acaso náo via que eu era ambas as coisas? Uganda era meu lugar, tinha passaporte ugandês. Ali teria passado toda a minha vida, à exceção dos meus cinco primeiros anos [...]. "Sou uma ugandesa com ascendência indiana", contestei. Pareceu satisfeito com minha resposta. Mas eu não podia ver que eu fui ambas as coisas. $\mathrm{O}$ corpo que se encontrava diante do meu interlocutor já estava classificado dentro das relações sociais, atravessadas pelo gênero, do sanduíche colonial [sandwich colonial]. Eu nâo podia simplesmente ser. (BRAH, 2011, p. 2425 , grifos da autora).

Essa impossibilidade de "simplesmente ser" faz-se presente nas pessoas negras, já que constroem sua identidade em um território caracterizado pela ausência de reconhecimento do continente africano, a menos que a ênfase seja o exotismo e o folclore. Inclusive, ao comentar o documentário "Orí", sobre a vida de Beatriz Nascimento, Wanderson Flor do Nascimento (2011) enfatiza que a construção da cultura brasileira foi influenciada fortemente pelas raízes africanas. Uma influência permeada pela identidade cultural, cujas “[...] marcas, os registros que nos fazem ver quem somos na relação com uma cultura e que faz entender que somos todas/os geradas/os, que somos, apenas numa relação com uma cultura e com uma história." (FLOR DO NASCIMENTO, 2011, p. 135, grifo do autor).

Essa relação conjunta é percebida na concepção de orí, a cabeça, " [...] mas não apenas a cabeça concreta (orí òde), que está acima de nossos pescoços,

5 Grada Kilomba utiliza essa expressão para referenciar-se à ação acadêmica frente aos corpos negros, a fim de se sentirem naquele local como "fora do lugar", ao contrário dos brancos, os quais são formados para se sentirem em casa. A ampliação é justamente que esse sentimento de "fora de lugar" é uma sensação dos corpos negros que, como em diáspora, enfrentam uma permanente falta de pertencimento nos locais que ocupam. 
mas a cabeça espiritual (orí inú), a cabeça que de algum modo representa o eu mais profundo." (FLOR DO NASCIMENTO, 2011, p. 139). Assim, os nossos caminhos são guiados no espaço-tempo pelo orí, que também simboliza o trânsito, o deslocamento entre lugares e pessoas. Por consequência, corpos negros necessitam do orí para se orientarem nos territórios deslocados e se afastarem do sentimento de "fora de casa".

Tal sentimento se intensifica pelo trânsito no Ocidente, que privilegia cada vez mais um pensamento sobre o indivíduo, com corpos determinados a certos espaços. Em decorrência, deslegitima o orí e o pertencimento à comunidade, o qual "[...] nos torna não apenas humanos no geral, mas uma pessoa em particular, daí a tamanha crueldade de destruição da identidade perpetrada pela colonizaçáo, pois retirou de nossas/os ancestrais uma parte de seu ser." (FLOR DO NASCIMENTO, 2011, p. 140). Assim, o ato de reconstituir o orí perpassa uma criação de espaço comunitário com os ancestrais, tendo como fim a denominada "cultura negra", uma cultura perpetuada nos espaços de resistência, por meio da criação e da recriação de um território mítico, histórico, pessoal, simbólico e material. O orí forma o elo mais profundo com a ancestralidade africana: "[...] orí representa uma relação com a origem do mundo na qual nos envolvemos neste momento, ao mesmo tempo em que representa a construçáo de uma nova história, de um novo nascimento," (FLOR DO NASCIMENTO, 2011, p. 142).

Assentados nessas perspectivas, podemos nos questionar: como produzir uma filosofia em território brasileiro, que tenha a África como um dos horizontes? Uma das possíveis respostas é considerar diferentes narrativas expressas pela cultura negra, seja na capoeira, seja no hip-hop, seja no samba; aqui trazemos a narrativas formadoras encontradas nos terreiros: os Itàns. Neles, as açóes das divindades do panteâo iorubano são contadas e permitem uma interpretação conceitual, não somente como guia e explicação dos caminhos da vida. Um dos que dialogam com a proposta deste artigo diz respeito a um Itàn da orixá Oyá/Iansã, pois nele percebemos um debate sobre a unificação entre natureza e cultura:

Ogun foi um dia caçar na floresta.

Ele ficou na espreita e viu um búfalo vindo em sua direção.

Ogun avaliou logo a distância que o separava

e preparou-se para matar o animal com sua espada.

Mas viu o búfalo parar e, de repente,

baixar a cabeça e despir-se de sua pele. 
Desta pele saiu uma linda mulher.

Era Oyá, vestida com elegância, coberta de belos panos,

um turbante luxuoso amarrado à cabeça

e ornada de colares e braceletes.

Iansã enrolou sua pele e seus chifres,

fez uma trouxa e escondeu num formigueiro.

Partiu, em seguida, num passo leve, em direção ao mercado da

cidade, sem desconfiar que Ogun tinha visto tudo.

(VERGER, 1997, p. 56).

Eduardo David de Oliveira (2007) compreende esse Itàn como uma narrativa acerca de um corpo que tem um duplo pertencimento: o búfalo e a mulher. Tal pertencimento possibilita também interpretar que o corpo é o território comum de natureza e cultura. Uma interpretação sustentada pela ideia de "veículo de passagem", conforme Maria Antonieta Antonacci (2002), pois, nesse Itàn, se evidencia a dinâmica e sobrevida da cultura através da natureza, ou seja, dos "corpos sem fronteiras":

[...] é como 'veículo de passagem' que sua pele de búfalo mais chama a atenção, por auxiliar a decifrar o enigma de corpos sem fronteiras, uma vez que Iansã se faz representar entre cultura/natureza, corpo investido com forças e energias de seres e elementos da natureza, e também com belos panos, vestes, adornos de sua cultura. (ANTONACCI, 2002, p. 173-174, grifos da autora).

Durante esse movimento de despir/vestir a pele de búfalo, essa divindade medeia o plano biocósmico, a organização vital entre humanos e demais divindades, a partir das expressóes, quer de "lealdade absoluta", quer de "extrema cólera". Essa duplicidade não significa que uma expressão pertence à dimensão da cultura e a outra à natureza, mas que tais dimensões se combinam em um corpo-território. Precisamente nesse corpo-território que a diáspora africana se manifesta, por encantar o mundo com as expressóes na fala, na dança, na culinária, nas vestimentas e na criatividade argumentativa em conformidade às "[...] normas de conduta dos antepassados." (OLIVEIRA, 2007, p. 207). Trata-se de uma conformidade que intensifica o corpo negro sendo um "corpo sem fronteiras" e, como tal, atravessa o "eu" com formas múltiplas de ser, em certo sentido, saindo do idealismo para se encarnar no mundo. Inclusive, se o Ocidente está estruturado no "sou, logo penso", 
isto é, o sujeito identifica-se consigo mesmo para distanciar-se do objeto, por outro lado, as concepçóes epistemológicas africanas se baseiam no "sou, relacionando-se com..." Uma relação que marca um processo de identificação do sujeito em conformidade com a sua posição diante do coletivo.

Com isso, os corpos da diáspora africana são influenciados por tal processo e, por maiores que sejam as açóes violentas e de controle, uma força histórica movimenta-se nesses corpos. Uma força alimentada por Oyá: “[...] a orixá que habita os nove mundos. É a orixá da mudança, e no meio da tempestade [...] rebrilham os relâmpagos como uma espada de fogo cortando os ares, impelindo a transformaçóes." (OLIVEIRA, 2007, p. 204). Com a diáspora africana tendo por característica uma mudança contínua dos corpos como estratégia de afirmação, então inferimos que a mudança trazida por Oyá fundamenta a diáspora africana.

Antes, é importante entender o sentido de diáspora que fundamentamos em Oyá, pois, como Avtar Brah (2011) adverte, diáspora possui uma variedade de significados e abarca muitas coisas. Com essa variação, qualquer tentativa de explicá-la é atentar às problemáticas específicas de movimentos entre naçóes, pessoas, capitais, bens e iconografias culturais. Por isso, para a autora, devemos conceituar a diáspora como "[...] a personificação de alguma consciência diaspórica transcendental. [...] E deveria ser visto como referência às genealogias historicamente contingentes." (BRAH, 2011, p. 227-228). Portanto, a palavra diáspora, mobilizada como fonte epistemológica, analisa as movimentaçóes humanas ao redor do globo e especifica interrelaçóes econômicas, política e culturais “[...] que constroem o 'comum' entre os distintos componentes de um grupo disperso.” (BRAH, 2011, p. 228).

Nessa construção confluem narrações de memória e de rememoração coletiva, no interior e no exterior de "comunidades imaginárias" que descrevem distintas experiências históricas. Isso expóe, para Brah (2011, p. 228), que "[...] o conceito de diáspora estabelece a diferenciação interna, tanto com o que existe entre as partes disseminadas pelo globo quanto por meio de uma população diaspórica particular." Em consequência, desdobra-se, ora em um debate com ênfase aos circuitos de poder enraizados em práticas de discursos institucionais, inscritas em experiências diaspóricas, ora na mobilização de uma concepção performativa multiaxial do poder. Por isso, devemos compreender a diáspora como um conceito que engloba o poder “[...] como algo relacional, que entra em jogo dentro de múltiplos espaços 
através dos micros e dos macro-campos." (BRAH, 2011, p. 228). Atentos a essa compreensão, podemos retomar Oyá.

Como lemos no Itàn, Oyá atravessa as formas mulher e búfalo, combinando natureza e cultura em um corpo. Uma junção que, para a mente ocidental, restrita à visão, fatalmente é entendida como uma manifestação em movimentos contrários e acionados em tempos diferentes. Contudo, retomando Oyěwùmí (2021), esse entendimento é sublimado por haver uma combinação dos sentidos, uma divergência não limitada a um caráter metassocial e que provoca a generificação das posiçôes sociais, ainda mais o Ocidente, ao considerar o outro da razão sendo o corpo, aquelas pessoas (negras, indígenas, trans), instantemente corporalizadas, são identificadas como predominadas pelo instinto e pelo afeto. Uma identificação, ao mesmo tempo, racializada e generificada para hierarquizar as posiçóes sociais e, principalmente, para a construção dos discursos legítimos para o ocidente.

Tais açôes de raça e gênero explicitam, para Oyěwùmí, a preocupação da cultura ocidental com os aspectos físicos humanos no interior da cultura bio-lógica, intensificadas na situação colonial. Principalmente dentro dessa situação, "[...] existe uma hierarquização de quatro, não duas, categorias. Começando no topo, eram: homens (europeus), mulheres (europeias), nativos (homens africanos), e Outras (mulheres africanas). As mulheres nativas ocupavam a categoria residual e não especificada do Outro." (OYĚWÙMÍ, 2021, p. 186). E essa estrutura de gênero e de raça acontece desde a antiguidade até à modernidade. Por exemplo, a concepção de cidadão é ontologicamente conceituada a partir do gênero: "A categoria cidadão, que tem sido a pedra angular de grande parte da teoria política ocidental, era masculina, apesar das muito aclamadas tradiçóes democráticas ocidentais." (OYĚWÙMÍ, 2021, p. 34-35).

Por outro lado, antes da colonização, na cultura Oyó, de tradição iorubá, o "físico" masculino ou feminino não eram categorias sociais e determinavam uma hierarquia generificada, mas o "[...] princípio que determinava a organização social era a senioridade, baseada na idade cronológica." (OYĚWU̇MÍ, 2021, p. 43). Por conseguinte, a hierarquia dependia do envolvimento de uma pessoa em uma situação particular. Assim, o corpo não se constitui em um elemento outro que precisa ser controlado, dominado, para que a razão ou a alma progrida a um determinado fim, mas um mesmo corpo fornece variadas perspectivas aos nossos olhares: "O exemplo clássico é a mulher que desempenhava os papéis de oba (governante), omo (prole), 
oko, aya, iyá (mãe) e aláwo (adivinhadora-sacerdotisa), tudo em um só corpo.” (OYĚWU̇MÍ, 2021, p. 43).

Com isso, perceber o corpo de Oyá/Iansã como aquele que comporta a mulher e o búfalo não se limita a identificar papéis sociais requeridos em certos momentos, contudo, como um trânsito entre o mundo e as vozes que coabitam no corpo. Tanto mais, conforme Vanda Machado (2013, p. 82), o corpo em certas situaçóes fala ritmicamente, "captando o seu vínculo com a totalidade do ser porque só o corpo inteiro nos serve de orientação. É comum ouvir-se das pessoas mais velhas: 'antes de escutar os outros, primeiro escute a sua cabeça'."

Justamente por essa escuta que a diáspora se torna fonte epistemológica para construirmos uma filosofia africana no Brasil. Uma construção "oríentada” (FLOR DO NASCIMENTO, 2011) para as vozes que nos circundam a todo o momento, por mais que ao nosso olhar estejam invisíveis.

\section{Consideraçóes Finais}

As análises feitas neste artigo procuraram articular a vivência no terreiro com o pensamento filosófico, na perspectiva de compreender a diáspora africana como fonte epistemológica. Uma vez assim compreendida, ela tem no corpo um dos elementos principais para a construção de uma filosofia que o privilegia, seja pelo posicionamento coletivo no mundo, seja pela uniáo entre natureza e cultura. As outras especificidades expostas no artigo referiram-se à memória inscrita no corpo negro responsável por revelar uma identidade ancestral, incitando uma criação da própria história, também ao cotidiano na produção de subjetividades a partir da tríade do ser, do fazer e do participar. Tais especificidades guiadas por Oyá/Iansã fazem os corpos em diáspora transformarem continuamente o "eu", criando territorialmente África. As últimas consideraçôes que serão propostas neste artigo partem do seguinte questionamento de Machado (2013, p. 86) sobre a condição de estudantes negras/os, diante da negaçáo ocidental de suas potencialidades:

Como mantê-los próximos dos mananciais das ciências, da filosofia e da arte, transitando pelos meandros da sociedade, vivenciando a tradição e memória sem amargar a vigilância da subalternização que nos cala enquanto vozes instituintes? 
Uma possível resposta está em perceber como a criação de novos papéis fora da ordem colonial requisita a afirmação de novos e novas protagonistas epistêmicos. Para tanto, o ato de escrever uma filosofia no Sul global acontece pelo ato de cultivar o "diálogo pela escuta", incluindo perguntas, respostas e, especialmente, expectativas. Uma tríade exposta pela percepção como via de intepretação de realidade, já que ela alarga os sentidos e transgride as fronteiras disciplinares e conceituais, para então afirmar que o "[...] pensamento de matriz cultural africana não comporta especialistas. Como generalistas, vive-se a necessidade da compreensão da totalidade dos seres." (MACHADO, 2013, p. 86). Porém, para isso, temos que compreender que somos protagonistas da nossa própria filosofia.

DANTAS, L. T. F. Philosophies in diaspora: terreiro's epistemologies and transformations of the self. Trans/Form/Ação, Marília, v. 45, p. 169-184, 2022. Edição Especial.

\begin{abstract}
This article deals with the african diaspora as an epistemological source and, mainly, think the implications for the production of african philosophy in Brazil. To this issue, the body will be emphasized as a means of communication with the visible or invisible world through the terreiro, establishing a relationship between experience and philosophical thought. Then, to base the diaspora, the narrative of orixá Oyá/Iansã will be interpreted as its axis the "body without borders" that mediates nature and culture. Finally, we propose a philosophy that articulates the encounter between the earth and the spiritual, the tradition and the modern based on a conceptual connection between Africa and Brazil.
\end{abstract}

Keywords: African philosophy. Diaspora. Terreiro. Body.

\title{
REFERÊNCIAS
}

ANTONACCI, M. A. Corpos sem fronteiras. Revista do Programa de Estudo PósGraduados em História e do Departamento de História - PUC/SP. São Paulo, n. 25, dez. 2002.

BALLESTRIN, L. The Global South as a Political Project. E-International Relation. 3 jul. 2020. Disponível em: https://www.e-ir.info/2020/07/03/the-global-south-as-apolitical-project/ Acesso em: 10 ago. 2020.

BRAH, A. Cartografías de la Diáspora. Identidades em cuéstion. Tradução de Sergio Ojeda. Madrid: Traficantes de Sueños, 2011. 
CUSICANQUI, S. R. Ch'ixinakax utxiwa: una reflexión sobre prácticas y discursos descolonizadores. Buenos Aires: Tinta Limón, 2010.

FLOR DO NASCIMENTO, W. Orí: a saga atlântica pela recuperação das identidades usurpadas. In: SOUZA, E. P. de (org.). Negritude, Cinema e Educaçáo. 1. ed. Belo Horizonte: Mazza, 2011. v. 3, p. 134-146.

KILOMBA, G. Memórias da plantação: episódios de racismo cotidiano. Tradução de Jess Oliveira. Rio de Janeiro: a Cobogó, 2017.

MACHADO, V. Pele da cor da noite. Salvador: UFBA, 2013.

MBEMBE, A. Formas Africanas de Auto-inscrição. Tradução de Patrícia Farias. Estudos Afro-Asiáticos, ano 23, n. 1, 2001.

MIGNOLO, W. Desobediência Epistêmica: a opção descolonial e o significado de identidade em política. Cadernos de Letras da UFF - Dossiê: Literatura, língua e identidade, n. 34, p. 287-324, 2008.

OLIVEIRA, E. Filosofia da Ancestralidade: Corpo e Mito na Filosofia da Educação Brasileira. Curitiba: Popular, 2007.

OYĚWÙMÍ, O. A Invençáo das Mulheres: construindo um sentido africano para os discursos ocidentais de gênero. Tradução de Wanderson Flor do Nascimento. Rio de Janeiro: Bazar do Tempo, 2020.

SODRÉ, M. Claros e Escuros: identidade, povo, mídia e cotas no Brasil. Petrópolis, RJ: Vozes, 2015.

SODRÉ, M. O Terreiro e a Cidade: a forma social negro-brasileira. Rio de Janeiro: Mauad X, 2019.

Recebido: $10 / 8 / 2020$

Aceito: 24/01/2021 